\title{
ICTV Virus Taxonomy Profile: Herpesviridae 2021
}

\author{
Derek Gatherer ${ }^{1}$, Daniel P. Depledge ${ }^{2}$, Carol A. Hartley³ , Moriah L. Szpara ${ }^{4}$, Paola K. Vaz ${ }^{3}$, Mária Benkő ${ }^{5}$, Curtis \\ R. Brandt ${ }^{6}$, Neil A. Bryant ${ }^{7}$, Akbar Dastjerdi ${ }^{8}$, Andor Doszpoly ${ }^{5}$, Ursula A. Gompels ${ }^{9}$, Naoki Inoue ${ }^{10}$, Keith W. Jarosinski ${ }^{11}$, \\ Rajeev Kaul ${ }^{12}$, Vincent Lacoste ${ }^{13}$, Peter Norberg ${ }^{14}$, Francesco C. Origgi ${ }^{15}$, Richard J. Orton ${ }^{16}$, Philip E. Pellett ${ }^{17}$, D. \\ Scott Schmid ${ }^{18}$, Stephen J. Spatz ${ }^{19}$, James P. Stewart ${ }^{20}$, Jakob Trimpert ${ }^{21}$, Thomas B. Waltzek ${ }^{22}$, Andrew J. Davison ${ }^{16, *}$ \\ and ICTV Report Consortium
}

\begin{abstract}
Members of the family Herpesviridae have enveloped, spherical virions with characteristic complex structures consisting of symmetrical and non-symmetrical components. The linear, double-stranded DNA genomes of 125-241 kbp contain 70-170 genes, of which 43 have been inherited from an ancestral herpesvirus. In general, herpesviruses have coevolved with and are highly adapted to their hosts, which comprise many mammalian, avian and reptilian species. Following primary infection, they are able to establish lifelong latent infection, during which there is limited viral gene expression. Severe disease is usually observed only in the foetus, the very young, the immunocompromised or following infection of an alternative host. This is a summary of the International Committee on Taxonomy of Viruses (ICTV) Report on the family Herpesviridae, which is available at ictv.global/report/herpesviridae.
\end{abstract}

Table 1. Characteristics of members of the family Herpesviridae

\begin{tabular}{|ll|}
\hline Example: & herpes simplex virus type 1 (JN555585), species Human alphaherpesvirus 1, genus Simplexvirus, subfamily Alphaherpesvirinae \\
\hline Virion & Spherical (150-200 nm) particles with condensed DNA core, icosahedral capsid, tegument and a lipid envelope containing glycoproteins \\
Genome & $125-241 \mathrm{kbp}$ of linear dsDNA \\
Replication & $\begin{array}{l}\text { Infection has lytic and latent phases; transcription occurs in the nucleus by a kinetic cascade; DNA replicates by a rolling-circle mechanism to generate concatemers, } \\
\text { from which genomes are cleaved and packaged into preformed capsids; virions mature in the cytoplasm }\end{array}$ \\
$\begin{array}{l}\text { Translation } \\
\text { Host range }\end{array}$ & Mammals, birds and reptiles \\
Taxonomy & Realm Duplodnaviria, kingdom Heunggongvirae, phylum Peploviricota, class Herviviricetes, order Herpesvirales; 3 subfamilies, $>10$ genera and $>100$ species
\end{tabular}

\section{VIRION}

Virions consist of a core, capsid, tegument and envelope (Table 1, Fig. 1) [1]. The core comprises the viral genome packaged into the capsid as a linear, dsDNA molecule. The capsid is a $T=16$ icosahedron containing 162 capsomers arranged as 150 hexons, 11 pentons and one portal. The tegument consists of inner and outer layers. The lipid envelope contains integral viral glycoproteins forming a network of spikes.

Received 11 August 2021; Accepted 14 August 2021; Published 27 October 2021

Author affiliations: 'Lancaster University, UK; ${ }^{2}$ NYU School of Medicine, New York, New York, USA; ${ }^{3} T h e$ University of Melbourne, Victoria, Australia; ${ }^{4}$ Pennsylvania State University, Pennsylvania, USA; ${ }^{5}$ Veterinary Medical Research Institute, Eötvös Loránd Research Network, Budapest, Hungary; ${ }^{6}$ University of Wisconsin-Madison, Madison, Wisconsin, USA; ${ }^{7}$ University of Cambridge, UK; ${ }^{8}$ Animal and Plant Health Agency-Weybridge, Addlestone, Surrey, UK; ${ }^{9}$ Virokine Therapeutics, London BioScience Innovation Centre, Royal Veterinary College, London, UK; ${ }^{10}$ Gifu Pharmaceutical University, Gifu, Japan; ${ }^{11}$ University of Illinois at Urbana-Champaign, Urbana, Illinois, USA; ${ }^{12}$ University of Delhi South Campus, New Delhi, India; ${ }^{13}$ Institut Pasteur du Laos, Vientiane, Lao PDR, Laos; ${ }^{14}$ University of Gothenburg, Gothenburg, Sweden; ${ }^{15}$ University of Bern, Switzerland; ${ }^{16}$ University of Glasgow, UK; ${ }^{17}$ Wayne State University School of Medicine, Detroit, Michigan, USA; ${ }^{18}$ Centers for Disease Control and Prevention, Atlanta, Georgia, USA; ${ }^{19}$ US National Poultry Research Center, Athens, Georgia, USA; ${ }^{20}$ University of Liverpool, UK; ${ }^{21}$ Freie Universität Berlin, Berlin, Germany; ${ }^{22}$ University of Florida, Gainesville, Florida, USA.

${ }^{*}$ Correspondence: Andrew J. Davison, andrew.davison@glasgow.ac.uk Keywords: Herpesviridae; ICTV Report; taxonomy. 001673 () 2021 


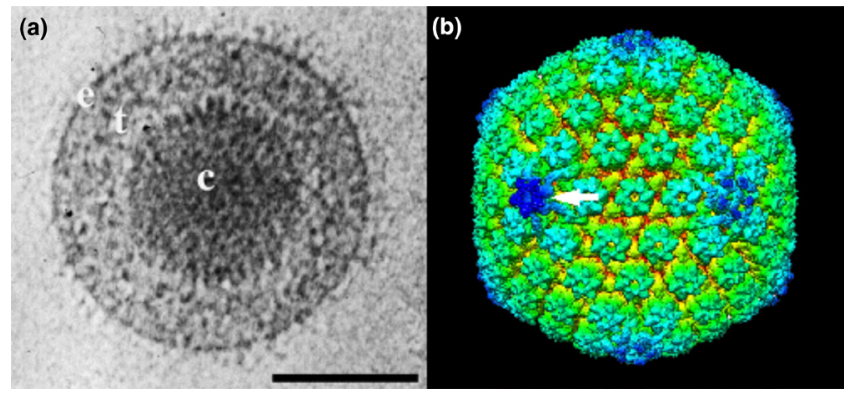

Fig. 1. Herpes simplex virus type 1 virion and capsid structure. (a) Electron cryo-microscopic image of a virion showing the capsid (c), tegument (t) and envelope (e). Scale bar, $100 \mathrm{~nm}$. From [2] with permission. (b) Three-dimensional image reconstruction of a capsid showing hexons, pentons and the portal (arrow). From [5].

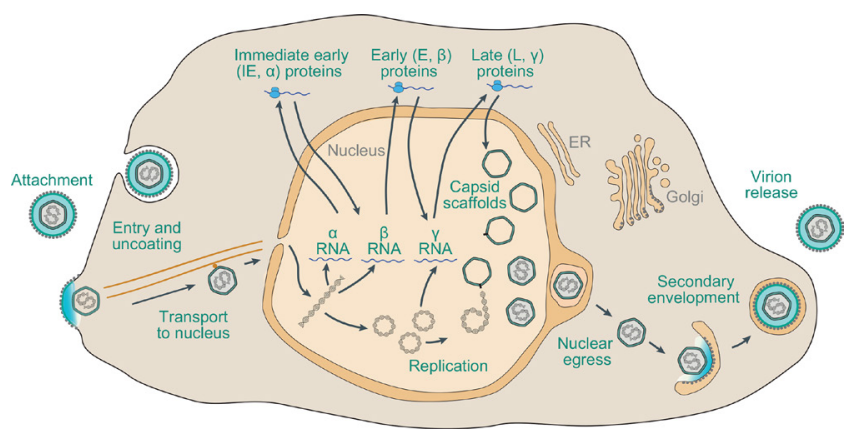

Fig. 2. Schematic representation of the lytic replication cycle of a representative herpesvirus in permissive cells.

\section{GENOME}

The genome is $125-241 \mathrm{kbp}$. The arrangement of direct or inverted repeats at the termini or internally results in several classes of genome architecture. The genome contains 70-170 genes encoding proteins, 43 of which are shared across the family, suggesting a common replication strategy [2]. Additional genes encoding nontranslated RNAs may be present.

\section{REPLICATION}

Herpesviruses have been discovered in a wide range of vertebrates (reptiles, birds and mammals). The most extensively studied animals are host to members of several species. Most herpesviruses have coevolved and sometimes cospeciated within a single host lineage, although foundational cross-species transmission events appear to have occurred. In general, lytic infection involves attachment and penetration by the interaction of virion envelope proteins with cell surface receptors, followed by entry via membrane fusion at the cell surface or after endocytosis (Fig. 2) $[3,4]$. The capsid uncoats and is transported to a nuclear pore, and the genome enters the nucleus. Transcription occurs in a kinetic cascade: immediate early genes encode regulatory functions, early genes encode the DNA replication complex and a variety of proteins involved in modifying host cell metabolism or immune responses, and late genes primarily encode virion proteins. Viral DNA synthesis occurs by a rolling-circle replication mechanism to generate concatemers, from which genomes are cleaved and packaged into capsids. Capsids bud through the inner nuclear membrane and are then de-enveloped by fusion with the outer nuclear membrane and released into the cytoplasm. Assembly of tegument proteins and secondary envelopment to generate mature virions occur in a Golgi or post-Golgi compartment. Virions exit the cell by exocytosis or cell-to-cell spread.

Herpesviruses are restricted in their natural host range and highly adapted to their hosts, with severe infection usually observed only in the foetus, the very young, the immunocompromised or in an alternative host. Typically, a primary, systemic infection is established via a cell-associated viraemia, followed by a latent phase in which dormant virus occasionally reactivates. Herpesviruses operate a range of modulation mechanisms to manage host immunity.

\section{TAXONOMY}

Current taxonomy: ictv.global/taxonomy. The family Herpesviridae includes three subfamilies, and belongs to the order Herpesvirales along with the families Alloherpesviridae and Malacoherpesviridae. This order is in turn classified alongside the order Caudovirales in the kingdom Heunggongvirae.

\section{RESOURCES}

Current ICTV Report on the family Herpesviridae: ictv.global/ report/herpesviridae.

\section{Funding information}

Production of this Profile, the ICTV Report and associated resources was funded by a grant from the Wellcome Trust (WT108418AIA).

\section{Acknowledgements}

The authors are the ICTV Herpesvirales Study Group. The ICTV Report Consortium is Stuart G. Siddell, Elliot J. Lefkowitz, Sead Sabanadzovic, Peter Simmonds, F. Murilo Zerbini, Donald B. Smith and Arvind Varsani.

Conflicts of interest

The authors declare that there are no conflicts of interest.

References

1. Grünewald K, Desai P, Winkler DC, Heymann JB, Belnap DM. Threedimensional structure of herpes simplex virus from cryo-electron tomography. Science 2003;302:1396-1398.

2. McGeoch DJ, Rixon FJ, Davison AJ. Topics in herpesvirus genomics and evolution. Virus Res 2006;117:90-104.

3. Krug LT, Pellett PE. The Family Herpesviridae: A Brief Introduction. Howley PM and Knipe DM (eds). In: Fields Virology. : Wolter Kluwer; 2021. pp. 212-234.

4. Arvin A, Campadelli-Fiume G, Mocarski E, Moore PS, Roizman B, et al. Human Herpesviruses: Biology, Therapy, and Immunoprophylaxis. Cambridge: Cambridge University Press; 2007

5. McElwee M, Vijayakrishnan S, Rixon F, Bhella B. Structure of the herpes simplex virus portal-vertex. PLoS Biol 2018;16:e2006191. 


\section{University Library}

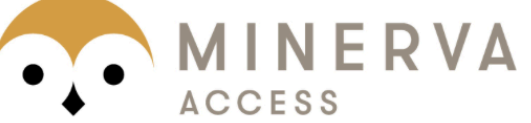

A gateway to Melbourne's research publications

Minerva Access is the Institutional Repository of The University of Melbourne

\section{Author/s:}

Gatherer, D;Depledge, DP;Hartley, CA;Szpara, ML;Vaz, PK;Benko, M;Brandt, CR;Bryant, NA;Dastjerdi, A;Doszpoly, A;Gompels, UA;Inoue, N;Jarosinski, KW;Kaul, R;Lacoste,

V;Norberg, P;Origgi, FC;Orton, RJ;Pellett, PE;Schmid, DS;Spatz, SJ;Stewart, JP;Trimpert, J;Waltzek, TB;Davison, AJ

Title:

ICTV Virus Taxonomy Profile: Herpesviridae 2021

Date:

2021-01-01

Citation:

Gatherer, D., Depledge, D. P., Hartley, C. A., Szpara, M. L., Vaz, P. K., Benko, M., Brandt, C. R., Bryant, N. A., Dastjerdi, A., Doszpoly, A., Gompels, U. A., Inoue, N., Jarosinski, K. W., Kaul, R., Lacoste, V., Norberg, P., Origgi, F. C., Orton, R. J., Pellett, P. E. ,... Davison, A. J. (2021). ICTV Virus Taxonomy Profile: Herpesviridae 2021. JOURNAL OF GENERAL VIROLOGY, 102 (10), https://doi.org/10.1099/jgv.0.001673.

Persistent Link:

http://hdl.handle.net/11343/296601

License:

CC BY 